\title{
Scavengers of Free Oxygen Radicals in Combination with Magnesium Ameliorate Perinatal Hypoxic-Ischemic Brain Damage in the Rat
}

\author{
MAGNUS THORDSTEIN, RALPH BÄGENHOLM, KLARA THIRINGER, AND \\ INGEMAR KJELLMER
}

Department of Physiology and Department of Pediatrics I, University of Göteborg, Göteborg, Sweden

\begin{abstract}
The effect of oxygen radical scavengers in combination with magnesium administered after a hypoxicischemic insult was evaluated in a model of perinatal brain damage. A mixture of scavengers of oxygen-derived free radicals (L-methionine, $0.2 \mathrm{~g}$; mannitol, $0.5 \mathrm{~g}$ ) and magnesium sulfate $(0.3 \mathrm{~g})$ per $\mathrm{kg}$ body weight was given to 34 1-wk-old rat pups immediately after a session of unilateral carotid artery ligation and $2 \mathrm{~h}$ of hypoxia $\left(8 \% \mathrm{O}_{2}\right.$ in $\left.\mathrm{N}_{2}\right)$. Thirty-four littermates served as controls; they received a placebo. At 3 wk of age, there was a significantly smaller reduction of hemisphere weight ipsilateral to the ligation in the treated animals compared with the controls $(0.7$ versus $8.8 \%$ of contralateral hemisphere weight median values, $p<0.01)$. The difference was especially marked for the most severe degrees of brain damage. Only one of the 34 treated animals, compared with 13 of 34 control animals, had a reduction of ipsilateral hemisphere weight $>25 \%$. The protection offered by the mixture used was larger than in previously published studies using this model and treatment after the hypoxic exposure with only one protective agent. It is concluded that a combination of oxygen radical scavengers and magnesium administered in the phase of resuscitation mitigates perinatal postasphyxial brain damage in the rat. An additive protective effect of different therapeutic strategies on the brain damage may be present in this situation. (Pediatr Res 34: 2326, 1993)
\end{abstract}

\section{Abbreviations}

LP, lipid peroxidation

NMDA, N-methyl-D-aspartate

ODFR, oxygen-derived free radical

During recent years, an increasing number of reports have corroborated the theory that ODFR and the subsequently in-

Received May 26, 1991; accepted February 5, 1993.

Correspondence: Magnus Thordstein, Department of Physiology, University of Göteborg, Medicinaregatan 11, 41305 Göteborg, Sweden.

Supported by grants from the Medical Research Council $(2592,2855)$, the Expressen Prenatal Research Foundation, the Frimurare-Barnhusdirektionen, Gothenburg; the General Maternity Hospital Foundation, the Magnus Bergvall Foundation, the Samariten Foundation; the Sven Jerring Foundation; the Expres sen Prenatal Research Foundation; the Swedish Society for Medical Research; the Linnea and Josef Carlsson Foundation; the Margaretha-hemmet Association; the Research Foundation of the National Swedish Association for Disabled Children and Young People; Ảhlén-Stiftelsen; the Bank of Sweden Tercentenary Foundation; the Royal Society of Arts and Sciences in Gothenburg, the Göteborg Medical Society, and the Faculty of Medicine, University of Göteborg. duced LP contribute to postischemic brain damage (1). These processes have also been implied to participate in perinatal brain damage $(2,3)$. In guinea pig and rat fetuses, hypoxia and hypoxiaischemia activate these systems $(4,5)$. Moreover, in 7-d-old rats, the ODFR scavenger allopurinol reduces hypoxic-ischemic brain damage when administered before the insult (6). An LP inhibitor (U74006F) given postasphyxia has also been demonstrated to provide protection in this model (7). Finally, these processes appear to be involved in perinatal pathology in humans also (8, 9). Intracellular calcium overload is considered to be of central importance to neurotoxic events $(10,11)$. Accordingly, flunarizine, a calcium channel blocker, offers partial protection against hypoxic ischemic brain injury in the 7 -d-old rat $(12,13)$. Magnesium is known to block the entry of calcium into cells by acting at both voltage-dependent and the NMDA receptor-associated channels (14). It has been demonstrated that magnesium reduces NMDA-mediated brain damage in perinatal rats (15).

In a previous study (16), we reported an improved cerebral function, compared with placebo-treated animals, in fetal sheep treated with a combination of ODFR scavengers, a calcium channel blocker, and magnesium. The animals were followed for $2 \mathrm{~h}$; thus, only short-term benefits of this treatment were investigated. The aim of the present study was to examine the possible long-term protective effect against cerebral damage of ODFR scavengers in combination with calcium channel blockade using magnesium. We used an established model of perinatal hypoxicischemic brain damage in the newborn rat $(17,18)$. Treatment was given after the insult to increase the clinical applicability of the results. We also wanted to evaluate a potential synergism of the two therapeutic strategies using a comparison with the effects of posttreatment with either inhibition of LP or excitatory amino acid neurotoxicity as previously reported $(7,19)$.

\section{MATERIALS AND METHODS}

Animal handling. Sprague-Dawley male and female rats (ALAB, Stockholm, Sweden) were housed separately with food (standard pellets, Ewos, Stockholm, Sweden) and water ad libitum under stable environmental conditions: 12-h light-darkness cycles, $55 \%$ humidity, and temperature of $22^{\circ} \mathrm{C}$. Mating was allowed for $24 \mathrm{~h}$ (d 0). Pregnant females were kept in separate cages from d 14 of pregnancy. Delivery took place on d 23 .

Experimental procedures. On postnatal d 8 (day of birth designated $\mathrm{d}$ 1) unilateral hypoxic-ischemic brain damage was induced in 70 pups from nine litters weighing $13 \pm 1.7 \mathrm{~g}$ (mean \pm SD). Each pup was placed on a thermostated table, and the left common carotid artery was ligated and cut between two ligatures with the pup under enflurane anesthesia $(2.0 \%$ for induction, 0.5 to $1.0 \%$ for maintenance; oxygen and nitrous oxide $1: 1$ ). Operation times for treated animals and controls were $12.5 \pm 0.6$ and 
$12.3 \pm 0.7 \mathrm{~min}$, respectively (mean \pm SEM). Postoperatively, the pups were returned to the dam, and $2 \mathrm{~h}$ after completion of the last operation, the pups were subjected to hypoxia in a thermostated chamber. Temperature was kept at 37.0 to $37.1^{\circ} \mathrm{C}$, and a preheated gas mixture of $8.15 \%$ oxygen in nitrogen saturated with water was passed through the chamber at a flow rate of 4.0 $\mathrm{L} / \mathrm{min}$. The exposure was terminated after $120 \mathrm{~min}$ or when two pups had died. Immediately thereafter, a mixture of ODFR scavengers ( $\mathrm{L}$-methionine, mannitol) and $\mathrm{MgSO}_{4}$ dissolved in distilled water or placebo (a solution of $\mathrm{NaCl}$ of the same osmolality $-710 \mathrm{mosmol} / \mathrm{kg}$ ) was given intraperitoneally. The solutions were administered in proportion to body weight $(0.1$ $\mathrm{mL} / 10 \mathrm{~g}$ ), producing the following dosages: $\mathrm{L}$-methionine, 0.2 $\mathrm{g} / \mathrm{kg}$; mannitol, $0.5 \mathrm{~g} / \mathrm{kg}$ and $\mathrm{MgSO}_{4}, 0.3 \mathrm{~g} / \mathrm{kg}$. At the time of injection, the pups were paired using body weight as the matching parameter. In each pair, one animal received the treatment solution and the other placebo. Thereafter, the pups were returned to the dam, and they were all transferred to the animal house.

On $\mathrm{d} 22$, the pups were killed by cervical dislocation and decapitated, and the brain was dissected out. Areas of obvious liquification were drained. The olfactorial tubercles, the cerebellum, and the brainstem were discarded, after which the hemispheres were separated in the midline and weighed with an accuracy of $0.1 \mathrm{mg}$ (AND, ER-60-A, A\&L Company, Ltd., Tokyo, Japan). The dissection of the brain was performed by an operator blinded to the mode of previous treatment.

The experimental protocol was approved by the animal ethics committee before the initiation of the study.

Statistical analysis. A two-stage selection procedure was used: first litters were chosen and then animals were matched for weight within each litter (20). The plan was regarded as a splitplot design with litters as main plots and pairs nested within litters. The litter effect and the levels of pairs within litters were regarded as random variables. Treatment effects were assumed to be fixed. After logarithmic transformation of the values, analysis of variance was performed to test the difference between the treatments on reduction of left versus right hemispheral weight.

One animal, assumed to have received the treatment mixture, was regarded by the computer program as an extreme outlier (weight of left hemisphere, $0.1674 \mathrm{~g}$; reduction of left hemisphere, $67.1 \%)$. On the presumption that it had not received this treatment (e.g. through intraintestinal injection), it and its pair-mate were disregarded. Thus, in the calculation, 68 animals were included.

\section{RESULTS}

No difference in mortality rate was seen between the groups during the 2 wk of observation (one in the treated versus none in the control group). The weights of the hemispheres of controls and treated animals are shown in Figure 1. The distribution of weights was symmetric for right hemispheres in both groups of animals. For left hemispheral weights, the distribution was skewed most markedly in controls, with a tail toward lower weights. The reduction of left hemispheral weight in percentage of the right is displayed in Figure 2. Again, a skewed distribution, most pronounced in the control group, was seen. The difference between the groups (medians 8.85 versus $0.72 \%$ ) was significant $(p<0.01)$. The difference was most marked at the tail end of the distribution. Thus, the fourth quartile of the weight reduction started at $36 \%$ for the controls and at $13 \%$ for the treated animals. Accordingly, only one treated animal, compared with 13 controls, had a weight reduction $>25 \%$.

\section{DISCUSSION}

A reduction of the degree of brain damage caused by hypoxiaischemia was demonstrated in this study; median reduction of hemisphere weight was $0.7 \%$ for treated versus $8.8 \%$ for control

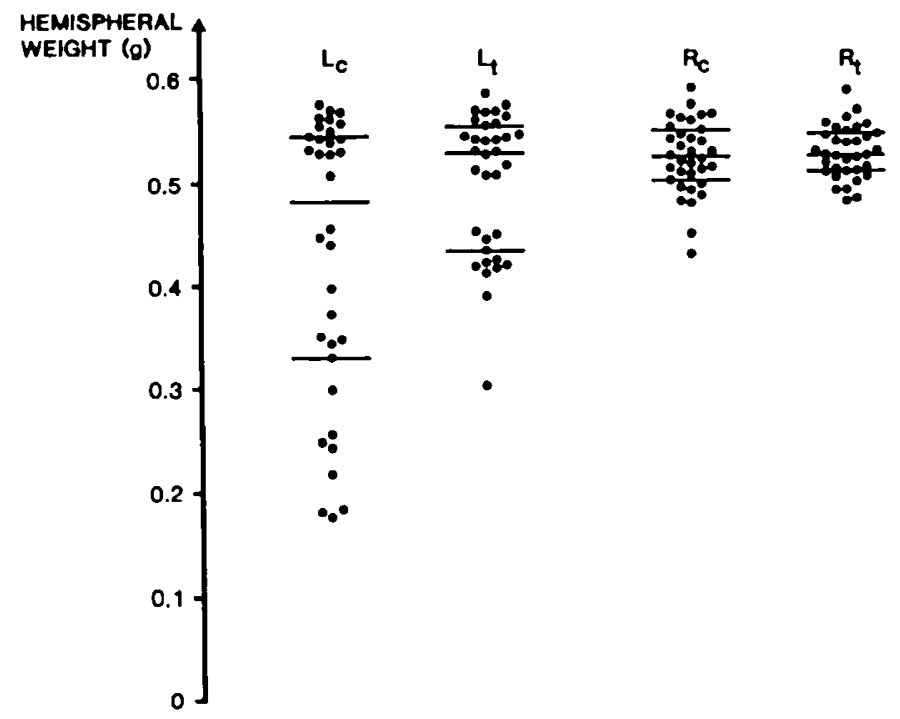

Fig. 1. Effect of asphyxia on absolute hemispheral weights. Weights of ligated left $(L)$ and nonligated right $(R)$ hemisphere in control $(c)$ and treated $(t)$ animals. Medians and first and third quartiles are indicated by horizontal lines.

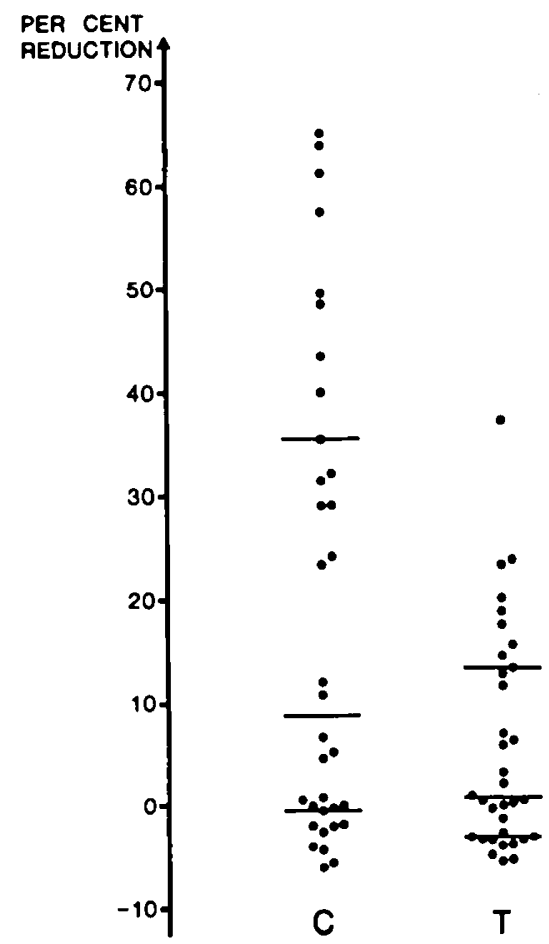

Fig. 2. Effect of asphyxia on relative hemispheral weights. Reduction of ligated left hemisphere weight as a percentage of that of the nonligated right hemisphere in controls $(C)$ and treated $(T)$ animals. Medians and first and third quartiles are indicated by horizontal lines.

animals (percentage of nonischemic hemisphere). Due to the skewed distribution, medians and quartiles were used for demonstration, and the split-plot variance method was used for statistical calculations. However, the median value tends to underestimate the degree of protection afforded by the treatment mixture in these experiments. This is demonstrated if mean values are calculated; the mean percentage reduction of hemisphere weight was $5.62 \pm 1.83 \%$ for treated and $19.01 \pm 4.00 \%$ for control animals (mean \pm SEM). The difference between median and mean values indicates that the protection was especially efficient against the most severe degrees of damage. Indeed, 
only one of 34 treated animals compared with 13 of 34 controls showed over $25 \%$ reduction of hemisphere weight (Fig. 2).

The degree of brain damage was assessed by weighing the hemispheres. We have evaluated this method and found a close correlation between the reduction of weight and both the morphometrically measured loss of brain structures and the reduction of somatosensory-evoked potentials (18). Thus, this simple method is adequate, at least for screening purposes. The weight of the right hemisphere was similar in the treated and control animals (Fig. 1). This indicates that the treatment did not affect overall brain growth. It also strengthens the results, inasmuch as it renders the measure of brain damage used more reliable.

It is reasonable to ascribe the protective effect of $\mathrm{L}$-methionine and mannitol to the inhibition of oxygen radical toxicity. Lmethionine has been shown to be a scavenger of hydrogen peroxide, singlet oxygen, hydroxyl radicals, and superoxide ions $(21-24)$. At least for the latter, the radical is reduced by the concomitant oxidation of methionine to methionine sulfoxide (24). Mannitol is a widely used scavenger of hydroxyl radicals $(25,26)$. Although mannitol does not cross the cell membrane, it might exert its effect by scavenging ODFR produced by the xanthine oxidase pathway residing in the brain capillary endothelium (27). At least later in the phase of resuscitation, mannitol may also reach the parenchyma due to breakdown of the bloodbrain barrier (28). It may be argued that mannitol exerted its effect through prevention of brain edema. However, this is unlikely, inasmuch as its capacity to protect from ischemic damage is not due to its osmotic properties (26). Moreover, in the model used, the development of brain edema is not related to changes of cerebral blood flow (29) or later developing brain damage (7). Finally, a lower dose of mannitol repeatedly administered reduces brain edema but does not protect from brain damage (30).

During asphyxia, the extracellular levels of excitatory amino acids (glutamate and aspartate) are elevated in the brain (31-33). Influx of extracellular calcium induced by activation of excitatory amino acid receptors and subsequent cellular calcium overload has been hypothesized to be the major etiologic event in excitotoxic brain damage $(10,11)$. Magnesium might interact with the toxicity of excitatory amino acids by blocking the calcium channel of the NMDA receptor $(14,15)$. As a blocker of NMDAmediated perinatal brain damage, it is as effective as several other NMDA receptor antagonists (34).

The treatment mixture that offered neuroprotection was supplied immediately after the hypoxic-ischemic insult. This is interesting from a clinical point of view, because it indicates that, at the time of resuscitation of the asphyxiated neonate, there are still therapeutic gains to be made. Moreover, the three agents used in the present study may all be used in humans. There are two previous studies in which this model has been used and treatment has been administered after the asphyctic episode. In one, an unspecific blocker of excitatory amino acid receptors, kynurenic acid (19), was used, in the other, an inhibitor of lipid peroxidation, the lazaroid U74006F (7), was administered. Although lipid peroxidation is thought to be the consequence of the formation of ODFR and although kynurenic acid may have a wider therapeutic spectrum than the calcium channel blocker magnesium, the results of those studies may be compared with that of the present investigation. The protective capacity of a treatment could be defined as the degree of brain damage in treated animals as compared with that in controls. Using kynurenic acid, the mean damage in treated animals was $67.2 \%$ of that in controls (19). The value for the lazaroid treatment was $61.6 \%$ (7). In the present investigation, the mean damage in treated animals was only $29.6 \%$ of the value in controls. This may be explained by findings in the adult brain where ODFR and excitatory amino acids reinforce each others' activities (35, 36). Such a parallel activation of the two systems has been reported to take place also in the brain of the fetal sheep during asphyxia $(31,37)$. The present results suggest that there are protective gains to be made using a mixture of agents that are active at different levels of the destructive process taking place after perinatal hypoxia-ischemia.

In conclusion, the demonstration of a significant reduction of the brain damage after the administration of a mixture of ODFR scavengers and magnesium suggests that ODFR and excitatory amino acids contribute to postasphyxial brain damage in the perinatal period.

\section{REFERENCES}

1. Siesjö BK, Agardh C-D, Bengtsson F 1989 Free radicals and brain damage. Cerebrovasc Brain Metab Rev 1:165-211

2. Kjellmer I 1988 Prenatal and intrapartum asphyxia. In: Levene MJ, Bennett MJ, Punt J (eds) Fetal and Neonatal Neurology and Neurosurgery. ChurchillLivingstone, Edinburgh, UK, pp 357-369

3. Vannucci RC 1990 Experimental biology of cerebral hypoxia-ischemia: relation to perinatal brain damage. Pediatr Res 27:317-326

4. Mishra OP, Delivoria-Papadopoulus M 1989 Lipid peroxidation in developing fetal guinea pig brain during normoxia and hypoxia. Dev Brain Res 45:129135

5. Iwasa H, Aono T, Fukozawa K 1990 Protective effect of vitamin E on fetal distress induced by ischemia of the uteroplacental system in pregnant rats. Free Radic Biol Med 8:393-400

6. Palmer C, Vannucci RC, Towfighi J 1990 Reduction of perinatal hypoxicischemic brain damage by allopurinol. Pediatr Res 27:332-336

7. Bàgenholm R, Andiné P, Hagberg H, Kjellmer I 1991 Effects of the 21aminosteroid U74006F on brain-damage and edema following perinatal hypoxia-ischemia in the rat. J Cereb Blood Flow Metab 11(suppl 2):S134(abstr)

8. Fish WH, Cohen M, Franzek D, Williams JM, Lemons JA 1990 Effect of intramuscular vitamin $E$ on mortality and intracranial hemorrhage in neonates of 1000 grams or less. Pediatrics 85:578-584

9. Pitkänen OM, Hallman M, Andersson SM 1990 Correlation of free oxygen radical-induced lipid peroxidation with outcome in very low birth weight infants. J Pediatr 116:760-764

10. Choi DW 1988 Glutamate neurotoxicity and diseases of the nervous system. Neuron 1:623-634

11. Siesjö BK, Bengtsson F 1989 Calcium fluxes, calcium antagonists and calciumrelated pathology in brain ischemia, hypoglycemia, and spreading depression: a unifying hypothesis. J Cereb Blood Flow Metab 9:127-140

12. Silverstein FS, Buchanan K, Hudson C, Johnston MV 1986 Flunarizine limits hypoxic-ischemia induced morphologic injury in immature rat brain. Stroke 17:477-482

13. Gunn AJ, Mydlar T, Bennet L, Faull RLM, Gorter S, Cook C, Johnston BM, Gluckman PD 1989 The neuroprotective actions of a calcium channel antagonist. Flunarizine, in the infant rat. Pediatr Res 25:573-576

14. Ascher P. Nowak L 1987 Electrophysiological studies on NMDA receptors. Trends Neurosci 10:284-288

15. McDonald JW, Silverstein F, Johnston MV 1990 Magnesium reduces Nmethyl-D-aspartate (NMDA)-mediated brain injury in perinatal rats. Neurosci Lett 109:234-238

16. Thiringer K, Hrbek A, Karlsson K, Rosén KG, Kjellmer I 1987 Postasphyxial cerebral survival in newborn sheep after treatment with oxygen free radical scavengers and a calcium antagonist. Pediatr Res 22:62-66

17. Rice JE, Vannucci RC, Brierley JB 1981 The influence of immaturity on hypoxic-ischemic brain damage in the rat. Ann Neurol 9:131-141

18. Andiné $P$. Thordstein $M, K$ Kellmer I, Nordborg $C$, Thiringer $K$, Wennberg $E$, Hagberg H 1990 Evaluation of brain damage in a rat model of neonatal hypoxic-ischemia. J Neurosci Meth 35:253-260

19. Andiné $P$, Lehmann A, Ellrén K, Wennberg E, Kjellmer I, Nielsen T, Hagberg H 1988 The excitatory amino acid antagonist kynurenic acid administered after hypoxic-ischemia in neonatal rats offers neuroprotection. Neurosci Lett 90:208-212

20. Edwards AL 1985 Split-plot design: analysis of variance. In: Experimental Design in Psychological Research. Harper \& Row, New York, pp 333-346

21. Caldwell KA, Tappel AL 1964 Reactions of seleno- and sulfoamino acids with hydroperoxides. Biochemistry 3:1643-1647

22. Ando W, Takata $T 1985$ Methionine and related compounds. In: Frimer AA (ed) Singlet $\mathrm{O}_{2}$, Vol III. CRC Press, Boca Raton, FL, pp 40-52

23. Blasig IE, Loewe $\mathrm{H}$, Ebert B 1988 Effect of troxerutin and methionine on spin trapping of free oxy-radicals. Biomed Biochim Acta 10/11:252-255

24. Scislowski PWD, Davis EJ 1987 Sulfur oxidation of free methionine by oxygen free radicals. FEBS Lett 224:177-181

25. Halliwell B 1978 Superoxide-dependent formation of hydroxyl radicals in the presence of iron chelates. FEBS Lett 92:321-326

26. Magovern Jr GJ, Bolling SF, Casale AS, Bulkley BH, Gardner TJ 1984 The mechanism of mannitol in reducing ischemic injury: hyperosmolarity or hydroxyl scavenger? Circulation 70(suppl I):91-95

27. Betz AL 1985 Identification of hypoxanthine transport and xanthine oxidase activity in brain capillaries. J Neurochem 44:574-579

28. Schleien CL, Kehler C, Shaffner H, Eberle B, Traystman R 199 I Blood-brain barrier disruption after cardiopulmonary resuscitation in immature swine. Stroke 22:477-483

29. Mujsce DJ, Christensen MA, Vannucci RC 1990 Cerebral blood flow and edema in perinatal hypoxic-ischemic brain damage. Pediatr Res 27:450-453 
30. Mujsce DJ, Towfighi J, Stern D, Vannucci RC 1990 Mannitol therapy in perinatal hypoxic-ischemic brain damage in rats. Stroke 21:1210-1214

31. Hagberg H, Andersson P, Kjellmer I, Thiringer K, Thordstein M 1987 Extracellular overflow of flutamate, aspartate, GABA and taurine in the cortex and basal ganglia of fetal lambs during hypoxic-ischemia. Neurosci Lett $78: 311-317$

32. Andiné P, Sandberg M, Bảgenholm R, Lehmann A, Hagberg H 1991 Intraand extracellular changes of amino acids in the cerebral cortex of the neonatal rat during hypoxic-ischemia. Dev Brain Res 4:115-120

33. Silverstein FS, Naik B, Simpson J 1991 Hypoxia-ischemia stimulates hippocampal glutamate efmux in perinatal rat brain: an in vivo microdialysis study. Pediatr Res 30:587-590
34. McDonald JW, Johnston MV 1990 Physiological and pathophysiological roles of excitatory amino acids during central nervous system development. Brain Res Rev 15:41-70

35. Dumuis A, Sebben M, Haynes L, Pin J-P, Bockaert J 1988 NMDA receptors activate the arachidonic acid cascade system in striatal neurons. Nature 336:68-70

36. Pellegrini-Giampietro DE, Cherici G, Alesiani M, Carla V, Moroni F 1988 Excitatory amino acid release from rat hippocampal slices as a consequence of free-radical formation. J Neurochem 51:1960-1963

37. Kjellmer I, Andiné P, Hagberg H, Thiringer K 1989 Extracellular increase of hypoxanthine and xanthine in the cortex and basal ganglia of fetal lambs during hypoxia-ischemia. Brain Res 478:241-247

\section{Announcement}

\section{Second Announcement and Call for Papers}

The World Congress on Rett Syndrome will be held in Antwerp, Belgium from October 8 to October 10, 1993. The Congress is organized by the Belgium Rett Syndrome Association under the gracious patronage of her Majesty the Queen of Belgium. Sessions will be held on clinical aspects of Rett Syndrome (variability, variants, epilepsy, scoliosis, nutrition) and on basic research (genetics, neuropathology, neurometabolism). A poster session will be held on Saturday, October 9th. For further information, contact the Congress Secretary, Vanherck Peter, Lil 26, B-2450 Meerhout, Belgium; phone: 32-14-309494; fax: 32-14-303157. 